Vidyodaya J., of Sci., (1992) Vol. 4, No. 1, pp: $233-242$

\title{
A PRELIMINARY STUDY OF SOME ASPECTS OF DISTRIBUTION OF PHOSPHOLIPIDS AND YIELD AND FLOW PROPERTIES OF HEVEA LATEX
}

\author{
S. Kasinathan, ${ }^{1}$ P. A. J. Yapa $^{2}$ and K. Balasubramanium ${ }^{3}$ \\ 1. C/O M. Namasivayam, \\ Malvan, Uduvil, \\ Sri Lanka.
}

2. Department of Botany, University of Sri Jayewardenepura, Nugegoda, Sri Lanka.

3. Department of Biochemistry, University of Jaffna, Jaffna, Sri Lanka.

Date Received : $09-09-1991$

Date Accepted : 28-09-1992

\begin{abstract}
The phospholipid content in various fractions obtained by high speed centrifugation of Hevea latex was studied. Distribution of phospholipid in latex as well as rubber of various clones of Hevea in relation to their yield and plugging index was compared. The rubber treated with sodium fluoride was found to.contain a higher phospholipid content. The polybag rubber, deproteinized rubber and autocoagulated rubber had more phospholipid content than conventional acid coagulated rubber. Hevea clones with high yield and superior quality of rubber, were found to have a greater phospholipid content than low yielding clones.
\end{abstract}

Key words: Distribution of Phospholipids yield, Hevea.

\section{Introduction}

The phospholipid is one of the major components of the lutoid , Frey Wysseling and rubber particle membranes of Hevea latex (Cockbain, 1984) Phosphatidic acid at a concentration of $0.2 \%$ in latex, was reported by Rhodes and Bishop (1930). It was shown by Altman and Kray (1940) that the crude phosphatide obtained from Hevea latex contain both choline and glycerophosphoric acid. Tristam (1949) obtained pure phosphatides $(0.09 \%$ of the latex) and separated them into choline and phosphatidic acid salt fractions by adding acetone and sodium chloride. Smith (1954) reported that the purified undegraded latex lipid consists of lecithin-containing reducing sugar $(51 \%)$, metal phosphatide containing Inositol and reducing sugar (10.5\%), phosphotidylethanolamine $(3 \%)$, triglyceride $(20 \%)$ and unsaponifiables $(15.5 \%)$. Ho et al. (1975) fractionated the neutral lipids and phospholipids from fresh 
latex of Hevea brasiliensis clones on thin layer chromatography. Hasma and Subramanium (1987) reported that the total lipids constituted about $1.6 \%$ of the latex, of which $54 \%$ was neutral lipids $33 \%$ glycolipids and $14 \%$ phospholipids.

This investigation was undertaken to study the phase distribution of lipids in different types of rubber, Attempt was also made to study the significance of these lipids in relation to yield potential of Hevea and to identify the phospholipids.

\section{Materials and methods}

Latex samples were collected from Hevea trees at Dartonfield Group of Rubber Research Board at Agalawatte. Latex was collected from about 15 trees, unless otherwise mentioned, and pooled into 3 samples and used for analysis as 3 replicates, mean values of which are expressed in results.

For each sample $40 \mathrm{ml}$ of latex was used, in weighed centrifuge tubes (capacity $60 \mathrm{ml}$,), one set 4 tubes containing $10 \mathrm{ml}$ of distilled water and the other $10 \mathrm{ml}$ of aqueous $1 \% \mathrm{NaF}$ solution in each. The latex samples were centrifuged at $14000 \mathrm{rpm}$ for $\mathbf{4 0} \mathrm{min}$ as described by Morris (1959), to give three main fractions namely rubber, serum and bottom fractions (Kasinathan, 1986). Polybag rubber was prepared by the method of Levique et al. (1975). The deproteinized rubber (DPNR) was prepared by the method described by Nadarajah et al. (1973) and the sodium fluoride treated rubber as described by Kasinathan (1986). The plugging index was determined by the method of Waidyanathe and Pathiratne (1971).

Samples of thin sheets of rubber $(5 \mathrm{~g})$ from each of the dry preparations were taken for Soxhlet extraction but in the case of bottom and serum fractions the entire weight of each was taken. Each sample was refluxed with $90 \mathrm{ml}$ of chloroform : methanol (2:1) for $16 \mathrm{~h}$ at $70^{\circ} \mathrm{C}$ (Folch, 1957). For clonal studies, the phospholipids were extracted from various Hevea clones as described by $\mathrm{Ho}$ et al. (1975). The extraction and separation of neutral lipids and phospholipids from dry rubber, rubber cream, and bottom fraction were carried out by the method shown in Fig.1.

\section{Results}

The distribution of phospholipids in various fractions obtained by centrifugation of field latex, collected in ice was studied. 


\section{Rubber Sample}

Refluxed with $90 \mathrm{ml}$ of $\mathrm{CHCl}_{3}: \mathrm{CH}_{3} \mathrm{OH}$; (2:1) mixture for $16 \mathrm{hrs}$ at $65-70^{\circ} \mathrm{C}$

Extract washed with $1 / 5$ volume $0.6 \%$ aqueous $\mathrm{NaCl}$

Centrifuged (5000 rpm for $15 \mathrm{~min}$.)

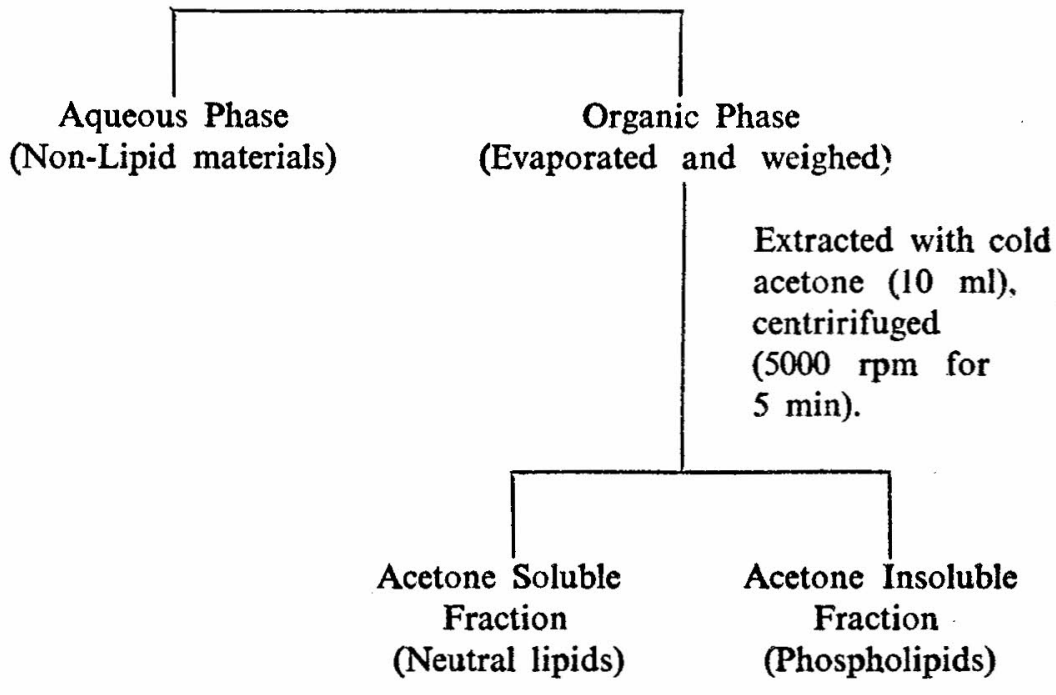

Fig. 1. Extraction and separation of Lipids from Dry Rubber, and Rubber Cream and Bottom Fraction

The results show (Table 1) that, of the total lipids in the control, the rubber fraction, the bottom fraction and the serum fraction, contained $22.4 \%, 4.24 \%$ and $0.45 \%$ phospholipids respectively while rubber fraction, the bottom fraction and serum had $24.9 \% 7.13 \%$ and $3.42 \%$ phospholipids respectively in the sodium fluoride treated latex. The results show (Table 1) that in the sodium fluoride treated latex, the phospholipids increased significantly in the bottom fraction, rubber fraction and serum. The phospholipid content in polybag rubber and sodium fluoride treated rubber compared to control crepe rubber was also increased by $45.5 \%$ and $97.4 \%$ respectively. 
Table 1. Distribution of Phospholipids and Neutral Lipids in various Fractions Obtained from Normal Hevea Latex and NaF - Treated Latex.

\begin{tabular}{ccc}
\hline Control & NaF \\
\hline Percent of Lipid content & Percent of Lipid content \\
in organic phase, of & in organic phase, of \\
each fraction $w / w$ & each fraction $w / w$ \\
\hline
\end{tabular}

\section{BOTTOM FRACTION}

Organic Phase

Phospholipid

Neutral lipid

\section{RUBBER CREAM}

Organic Phase

Phospholipid

Neutral lipid

SERUM PHASE

Organic phase

Phospholipid

Neutral lipid
13.9

4.24

8.86

84.7

22.0

60.8

0.85

0.45

0.37
16.7

7.13

7.42

79.7

24.9

36.8

Note 1 Mean values of two different experiments with three replicates in each $($ DRC $=43 \%$

Total Solid $=44.3 \%$ )

2 Lipid content in each of organic phase constitutes total lipid in each fraction and is approximately the sum of phospholipids and neutral lipids.

Table 2, Percentage Distribution of Phospholipid, Neutral Lipid in Control Crepe. Sodium Fluoride Treated Latex Crepe Polybag Rubbers.

\begin{tabular}{cccc}
\hline Lipid & $\begin{array}{c}\text { Crepe Rubber } \\
\text { (Control) } \\
\% W / W\end{array}$ & $\begin{array}{c}\text { Sodium Fluoride } \\
\text { Treated Rubber } \\
\% W / W \% \text { Chang } e_{*} \% W / W\end{array} \begin{array}{c}\text { Polybag Rubber } \\
\%\end{array}$ \\
\hline Total lipid & 2.676 & $3.510+31.17$ & $2.381-11.0$ \\
(Organic phase) & \pm 0.34 & \pm 0.38 & \pm 0.3 \\
Neutral lipid & 2.064 & $2.555+23.79$ & $1.842-10.76$ \\
& \pm 0.26 & \pm 0.64 & \pm 0.043 \\
Phospholipid & 0.387 & $0.764+97.4$ & $0.563+45.5$ \\
& \pm 0.146 & \pm 0.24 & \pm 0.04 \\
\hline
\end{tabular}

Mean \pm SD experimental values of three rubber samples. Percentage on $100 \mathrm{~g}$ of rubber.

* change compared to control (crepe rubber) 
Clonal distribution of phospholipids as a percent of total lipids of Hevea clones RRIC 45, PB 86 and RRIC 7 were 70,7, 65.9 and 64.9 respectively and their plugging indices together with those of RRIC 52, RRIM 501 and Tjir 1 are shown in Table 3.

TABLE 3. THE CLONAL VARIATION OF PHOSPHOLIPID, NEUTRAL LIPID (\%) IN RELATION TO PLUGGING INDEX'

\begin{tabular}{|c|c|c|c|c|c|c|}
\hline \multirow[b]{2}{*}{ Organic Phase } & \multicolumn{2}{|c|}{$* * *$} & \multicolumn{2}{|c|}{$* * *$} & \multirow{2}{*}{$\begin{array}{c}* * \\
R R I M 501\end{array}$} & \multirow[b]{2}{*}{ Tjir 1} \\
\hline & RRIC 45 & $P B 96$ & RRIC7 & RRIC52 & & \\
\hline Phospholipid & 79.3 & 76.9 & $72 . c 6$ & 71,4 & 60.4 & 60.0 \\
\hline Neutral lipid & 21.2 & 22.7 & 21.4 & 24.4 & 22.43 & 22.7 \\
\hline Lipid residue & - & 0.1 & 6.2 & 4.2 & 16.5 & 17.0 \\
\hline Pluggirg Index & 2.4 & 3.1 & 3.38 & 3.59 & 3.88 & 5.2 \\
\hline
\end{tabular}

The phospholipid content in the low and high yielding trees are shown in Table 4. The phospholipids and the volume of the latex in the high yielding trees were significantly higher than in the low yielding trees while plugging index was significantly decreased.

TABLE 4. DISTRIBUTION OF PHOSPHOLIPID, NEUTRAL LIPID ( $\%$ IN RELATION TO YIELD AND PLUGGING INDEX (CĹONE RRIC 45)

\begin{tabular}{lcc}
\hline $\begin{array}{l}\text { Organic Phase } \\
\text { Lipid }\end{array}$ & $\begin{array}{c}\text { Low Yielding } \\
\text { Trees }\end{array}$ & $\begin{array}{c}\text { High Yielding } \\
\text { Trees }\end{array}$ \\
\hline Phospholipid & 57.6 & 86.26 \\
Neutral lipid & 27.2 & 13.26 \\
Jsoprene & 15.1 & 6.45 \\
Volume of latex (ml) & 70.5 & 426.0 \\
Plugging Index & 2.4 & 1.83
\end{tabular}

Note - Mean values of two types of trees ccvering about 15 trees for
cach type in sampling

The effect of various types of coagulation of latex on phospholipid content is shown in Table 5. The coagulants were formic acid ( $2 \%$ ), papain $(0.05 \%)$ and bacreria (autocoagulation). Autocoagulation resulted in a rubber with the highest phospholipid content followed by papain \& acid coagulations. 
TABLE 5. EFFECT OF VARIOUS TYPES OF COAGULATION ON PHOSPHOLIPID

\begin{tabular}{lccc}
\hline Lipid & $\begin{array}{l}\text { Formic Acid } \\
\text { Coagulated } \\
\text { Crepe Rubber } \\
\text { (Control) } \\
\% W / W\end{array}$ & $\begin{array}{c}\text { Papain } \\
\text { Coagulated } \\
\text { Rubber }\end{array}$ & $\begin{array}{c}\text { Autocoagulated } \\
\text { rubber }\end{array}$ \\
\hline Total lipid & 2.498 & 2.396 & $\% W W W$ \\
Phospholipid & .46 & 0.56 & 0.614 \\
Neutral lipid & 2.006 & 1.898 & 2.006 \\
\hline
\end{tabular}

Percentage distributicn on dry rubber

Thin layer chromatography of phospholipids extracted from the bottom fraction is shown in Fig 2 and it showed the presence of seven compounds when sprayed with ammonium molybdate reagent which is specific for phosphate containing lipids (Vasdovisky \& Kostetsky, 1968 and Skidmore \& Enterman, 1962). Similar results were obtained with the phospholipid extracts from the rubber phase. The spots $\mathrm{E} \& \mathrm{G}$ had similar $\mathrm{Rf}$ values to phosphotidylcholine and phosphotidylethanolamine. The thin layer chromatograms when sprayed with Dragendroff reagent gave an orange yellow spot at $\mathrm{E}$ indicating a choline containing phospholipid. The spot $G$ gave a positive test with ninhydrin, indicating that it could be phospotidylethanolamine.

When TLC plates after developing, were exposed to iodine vapour ten brown spots were observed indicating the presence of unsaturated aliphatic chain in these phophoslipids. Two of them corresponded to phosphotidyl choline and phosphotidylethanolamine. The phophosmolybdate positive spots $\mathrm{D}$ and $\mathrm{E}$ gave a positive colour with a-napthol reagent Fig 3.

\section{Discussion}

Of the three fractions obtained from centrifugation of latex, the rubber fraction had a higher phospholipid content than the bottom fraction (Table 1). This indicates that phospholipids are associated more with the rubber fraction.

There is an increase in the phospholipids content in NaF treated latex when compared to the control, untreated latex in all three fractions and the changes were $79 \%$ in the rubber phase, $16.7 \%$ in the bottom fraction and $37.2 \%$ in the serum (on total organic lipid phase), (Table 1). The addition of NaF into latex followed by formic acid coagulation resulted in an increase in the phospholipid content of the dry rubber compared to conventional formic acid coagulated rubber where no $\mathrm{NaF}$ has been added (Table 2). In a comparative assessment based on the colour intensity of TLC spots, where identical 
quantities were applied, it was found that $\mathrm{NaF}$ treated samples had more phospholipids than untreated latex samples. This again indicates an inhibition of phospholipase-D activity by sodium fluoride, as anticipated. The inhibition of enzyme phospholipase- $D$ extracted from cabbage, by fluoride ions has been reported by Kates (1958). In polybag rubber, a considerable increase (i.e. $45 \%$ ) in phospholipid content was observed (Table 2). The increase in phospholipid content in polybag rubber may be due to an inactivation or denaturing of the phospholipase-D enzyme present in the latex by the bacterial action or due to the temperature factor.

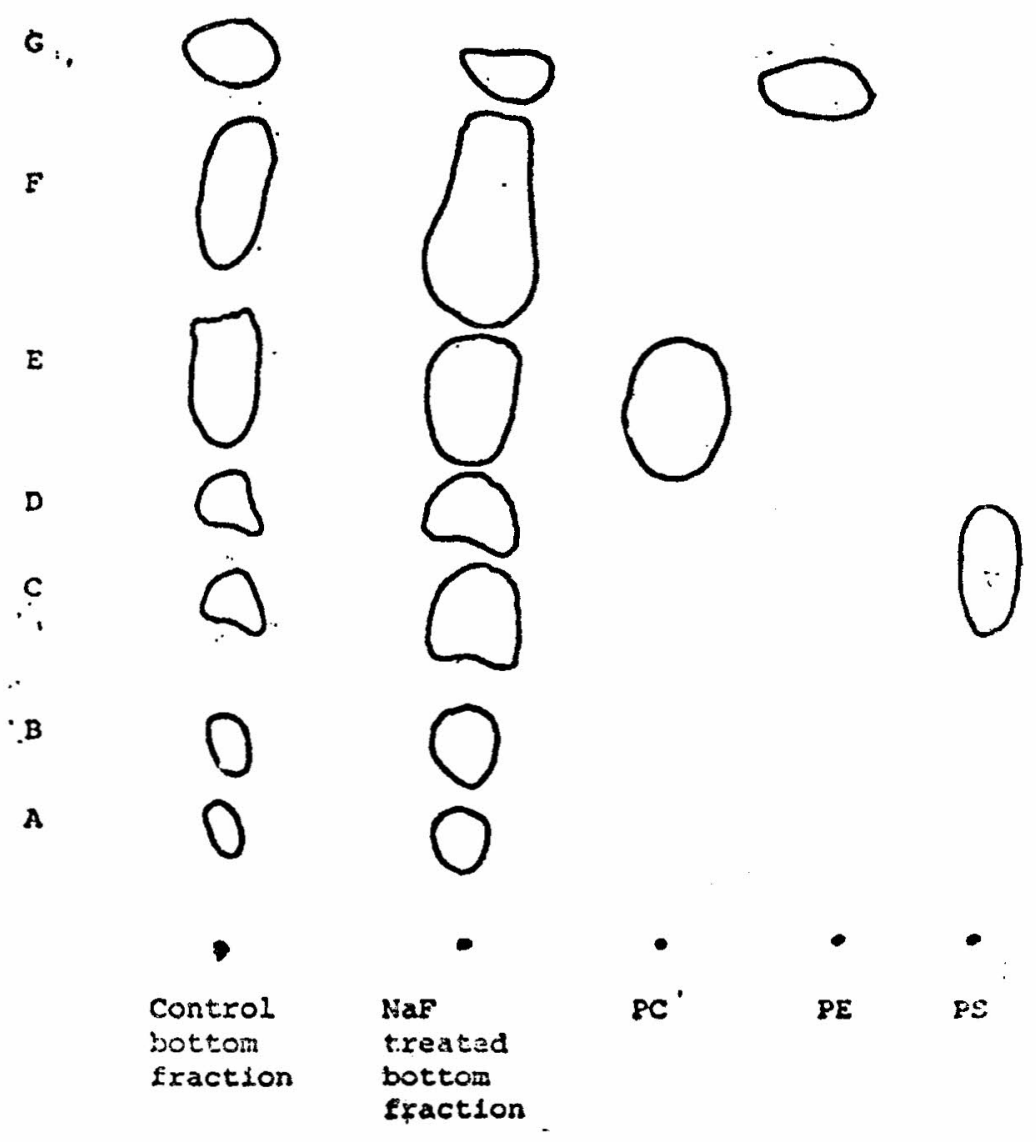

Fig. 2. Thin layer chromatogram on silica gel $G$ showing the phospholipid distribution in bottom fractions of centrifuged latex with and without sodium fluoride (NaF). Authentic samples: Phosphatidylcholine (PC); Phosphatidylethanolamine (PE); Pshosphatidylserine (PS); Solvent system chloroform-methanolwater $(65 ; 25: 4)$. Spray reagent ammonium molybdate. Spotting concentration $35 \mu \mathrm{l}$, clone PB86. Spots colour blue. 
It was also observed that varoius types of coagulants affect the phospholipid content (Table 5). The papain treated rubber (also known as DPNR) and autocoagulated rubber had more phospholipids than the control crepe where the increases were $19.1 \%$ and $88.9 \%$ respectively. This increase could be due to the denaturing of phospolipase- $D$ by the enzyme papain in the case of papain treatment and bacterial degradation in autocoagulation (Table 5).

There is a considerable variation in the distribution of phospholipids among various Hevea clones. The high yielding clones RRIC 45 and PB 86 which are known to yield latex of good quality and with improved properties have more phospholipid than clones such as RRIC 7. Tjir 1 and RRIM 501. The plugging index which gives a measure of the flow properties of latex was very low in RRIC 45 and PB 86 clones when compared with those of Tjir 1, RRIC 52 and RRIM 501 (Waidyanatha, 1971). (Table 3). This points to the possibility of phospholipids having some relationship with the plugging index which is known to be directly related to latex flow and the field yield.

The rubber from the high yielding trees also had a higher phospholipid content than that from low yielding trees (Table 4). This suggests that phospholipids play a role in the flow pattern and the yield, by maintaining the stability of the rubber and lutoid particles during the latex flow, phospholipid is one of the major constituents of the particles memberane. The interfacial film in freshly tapped NR latex consists mainly of protein and lipid material possibly in the form of a complex (Cockbain, 1948).

Boatman (1966), Buttery and Boatman (1967) observed that the decrease in the rate of flow is due to an obstruction to the flow commencing soon after tapping. This obstruction is located at or near the cut ends of the vessels and is the result of being plugged internally with coagulated rubber. The rapidity of plug formation is an important physiological characteristic which probably is genetically determined (Milford et al, 1980. It may be possible that due to the instability of the rubber and lutoid particles, membrane breaks and the acid formed by the bacterial degradation of lipids and carbohydrates, coagulate the rubber.

Smith (1954) has shown the presence of choline and ethanolamine in hydrolysates of phosphatides of NR latex. Ho et al (1975) have observed six spots reacting positively with ammonium molybdate reagent but only identified two, namely phosphotidylcholine and phosphotidylethanolamine. The presence of phosphotidylinositol was confirmed by Hasma and Subramanium (1987). The infra-red spectrum and absorption pattern of the eluted substance from the spot $E$ of the sample were similar to that of the authentic phosphotidylcholine which further confirms its identity, in the present study. 
Four spots were obtained when the TLC plates were sprayed with anaphthol reagent which is specific for glycolipids (Fig 3). Two of them namely the spots $D$ and $F$ were also positive to ammonium molybdate reagent which indicates that these two glycolipids are the phosphate containing glycolipids. Smith (1954) has shown by paper chromatogra'phy, the presence of glucose and galactose in the phosphatide fraction of NR latex. The presence of these sugars in phosphatide hydrolysate was also reported by Trisam (1942). Hasma and Subramanium (1987) have also reported the presence of several glycolipids in Hevea latex. The exact chemical nature of these various types of lipids including glycolipids would certainly be of help in unraveling the reasons for clonal variability in properties of hevee rubber.

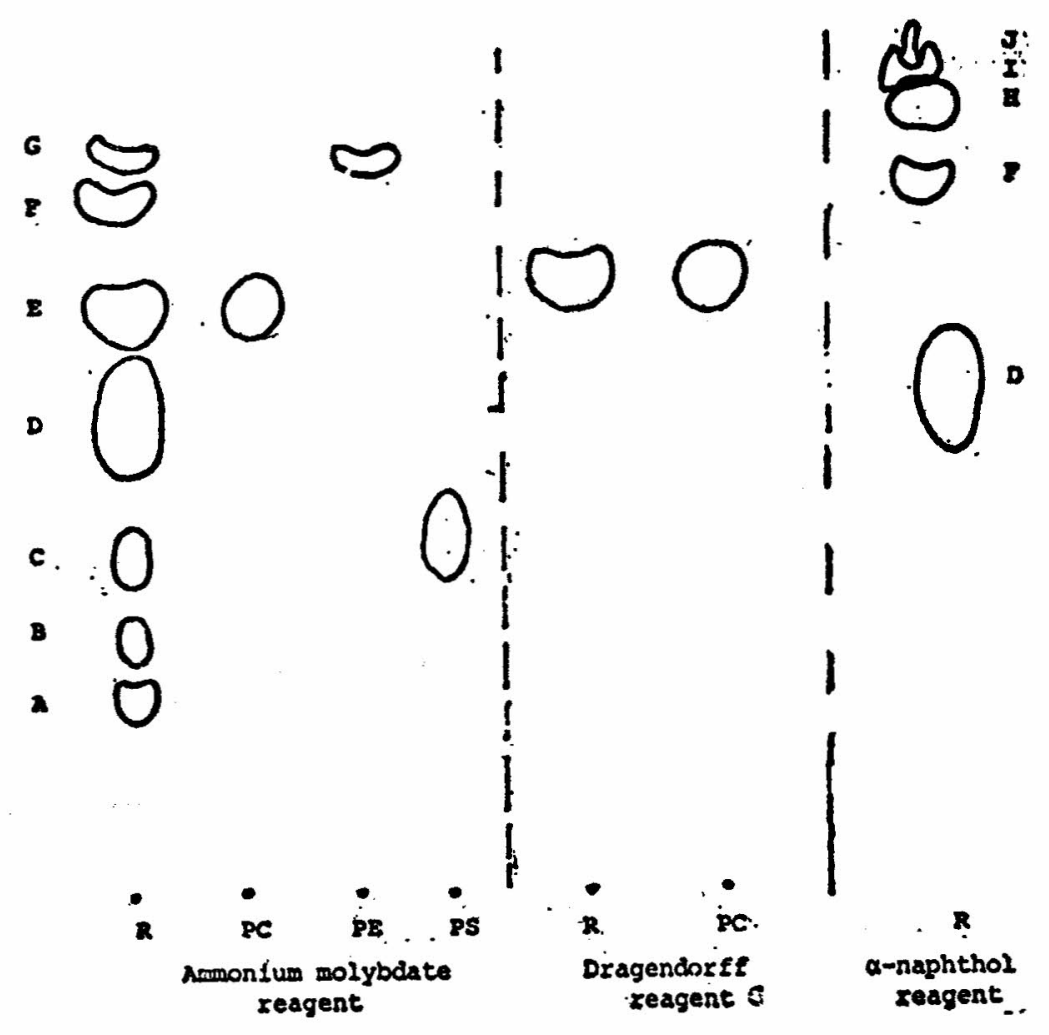

Fig. 3. Thin layer chromatogram sprayed with (1) ammonium molybdate reagent, (2) Dragendroff reagent, (3) a-naphthol reagent. Solvent system: chloroform-methanol-water $(65: 25: 4)$ Silica gel G plate, Rubber sample (R), Phosphati-dylcholine (PC), Phosphatidylethanolamine (PE), phosphatidylserine (PS), Spots on portion 1- blue Potion 2-orange yellow Portion 


\section{References}

Altman, R.F.A. and Kray, G.M. (1940) Isolation and identification of lecithins from Hevea latex Rubbercult Nest-Indie, 24, 58

Boatman, S.G. (1960) Preliminary physiological studies on the promotion of latex flow by plant growth regulators J.Rubb.Res.Inst.Malaya, 19, 243-247

Buttery, B.R.A. and Boatman, S.G. (1967) Effects of tapping wounding and high growth regulators on turgor pressure in Hevea brasiliensis Arg. J.Expt.Bot. 18, 644-659

Cockbain, E.G. (1948) Colloidal stability of rubber latex. Role of the interfacial film India Rubb. J. 114, 451-455

Folh, J.,Lees, M. and Sloane Stanley, G.H. (1957). Isolation and purification of total lipids J.Biochem. 226, 497-509

Hasma, $\mathrm{H}$ and Subramanium , A. (1987) Composition of lipids in latex of Hevea brasiliensis J.Nat.Rubb.Res.1, 30-40

Ho, C.C.,Subramanium, A. and Young, W.M. (1975) Lipids associated with the particles in Hevea latex Proc.Internat.Rubb.Conf.Kuala Lumpur 2, 441-456

Kasinathan, S. (1986) A study of phospholipids and their significance in Hevea brasiliensis latex Thesis submitted for the degree of Master of Philosophy, University of Colombo.

Leveque, J.,Loyen,G. and Dron,B. (1957) Commercial experience in tapping and processing polybag rubbers Proc. Inteinat.Rubb.Conf.Kuala Lumpur 2, 427-433

Milford, G.F.J.,Paardeeper, E.C. and Ho Chai Yee (1968) Latex vessel plugging. Its importance to yield and clonal behaviour. J.Rubb.Res.Inst.Malaya 21, 247-282

Moir, G.F.J. (1959) Ultracentrifugation and staining of Hevea latex Nature 184, 1626

Nadarajah,M.,Yapa, P.A.J.,Balasingham, C.G. and Kasinathan, S. (1973) The use of papain as a biological coagulant for natural rubber latex Quart. J.Rubb. Res. Inst. Sri Lanka 50, 143-150

Rhcdes,' E. and Bishop, R.P (1930) The lipid of Hevea latex J.Rubb.Res. Inst.Malaya 2, 125

Skidmore, W.D. and Enterman, C. (1962) Two dimensional thin layer chromatography of rat liver phosphatides J. Lipid Res. 4, 42-47

Smith, R.H. (1954) The phosphatides of the latex Hevea brasiliensis carbohydrate and polyhdroxy constituents Biochem J. 56, 140-144

Tristam, G.R. (1942) The phosphatides of Hevea brasiliensis Biochem. J. 36, 400--405

Vaskovisky, V.F. and Kostetsky, E.Y. (1968) Modified spray for the detection of phospholipids on thin layer chromatograms J.Lipid Res. 9, 396

Waidyanatha, U.P. de S. and Pathiratne, L.S.S. (1971) Studies on latex flow patterns and plugging indices of clones RRIC Quart. J. 48, 35-47 